\title{
A 15 yr climatology of derecho-producing mesoscale convective systems over the central and eastern United States
}

\author{
Mace L. Bentley*, Jesse A. Sparks \\ Department of Geography, Northern Illinois University, DeKalb, Illinois 60115-2896, USA
}

\begin{abstract}
A 15 yr (1986-2000) climatology of derecho-producing mesoscale convective systems (DMCSs) is presented in order to better delineate their spatial and temporal patterns. Several significant results emerged from the analysis, including the development of the NW flow corridor as the dominant derecho activity region in the climatology. Results suggest that, as the sample size of DMCSs increases (230 events), the prominent derecho activity corridors across the eastern US become located in the northern Plains through the Ohio Valley, with a secondary maximum in the southern Plains. Evidence further suggests that climatological factors strongly control the distribution of derechos. For example, an anomalously strong $500 \mathrm{hPa}$ height gradient existed coincident with the northern US derecho activity corridor. Another aspect of derecho development is related to the temporal distribution. Evidence suggests that derecho systems tend to occur in groups or 'families', several events occurring within several days. The synoptic environment also appears to be responsible for activating these corridors and providing an environment conducive to DMCS grouping.
\end{abstract}

KEY WORDS: Derecho $\cdot$ Climatology $\cdot$ Mesoscale convective systems

\section{INTRODUCTION}

Organized clusters of thunderstorms capable of producing severe straight-line windstorms frequently affect regions of the United States east of the Rocky Mountains (Bentley \& Mote 1998, hereinafter BM98). Wind gusts within these windstorms, known as derechos, are at least $26 \mathrm{~m} \mathrm{~s}^{-1}$, with often higher gusts (Johns \& Hirt 1987, hereinafter JH87). Concentrated severe wind gusts continuing along an extensive path create the potential for enormous property losses and threat to human life. One such event occurred on 31 May 1998, affecting 5 states from western Minnesota to upstate New York. The system caused an estimated US \$243 million in property damage and US \$32 million in agricultural losses, while being responsible for 280 injuries and 5 deaths along its $1600 \mathrm{~km}$ path (Storm Data 1998). While not all derecho-producing mesoscale convective systems (DMCSs) result in destruction of this magnitude, they still expose a widespread region to extreme wind damage, and further investigation into their temporal and spatial distribution is merited.

Recently, BM98 examined the distribution of DMCSs occurring throughout the eastern US for the $10 \mathrm{yr}$ period of 1986-1995. An update to this climatology is performed to include the next $5 \mathrm{yr}$ period of 1996-2000. This examination serves to assist individuals in better resolving the spatial and temporal distributions of DMCSs and to highlight consistencies and changes in the 10 yr climatology. The most significant finding in this update is the emergence of the northern tier (i.e. upper Great Plains, upper Midwest, and Great Lakes regions) corridor as the dominant one in the climatology. Although an active corridor in the $10 \mathrm{yr}$ investigation, BM98 results suggested the primary maximum of DMCS occurrence to be in the southern Plains. Additionally, the development and location of persistent 
warm season anticyclones appears to favour and subsequently activate some derecho corridors, particularly in the Great Plains and northern tier of the US. Once synoptic-scale conditions are favourable for DMCS development, the DMCSs, after being initiated by localized forcing, tend to group or 'train' over a similar geographic region. In other words, a specific region may experience a series of DMCSs over successive days.

\section{DATA/METHODOLOGY}

The primary data source for this investigation is the Storm Prediction Center's Severe Plot 2.0 software (Hart 2000) containing a database of severe convective wind events $\left(\geq 26 \mathrm{~m} \mathrm{~s}^{-1}\right)$ and documented wind-damage reports, taken from the NOAA publication Storm Data. In order to assure consistency, the identification criteria used in BM98 is also used in this investigation (Table 1). The derecho events were then mapped to facilitate visual inspection and ensure temporal and spatial continuity. Individual wind damage reports from each derecho event were then gridded on an $1^{\circ} \times 1^{\circ}$ grid-cell domain using the Interactive Data-common Language (IDL) so that contours could be generated in order to discern the geographical and frequency distribution of DMCSs.

Table 1. Criteria used to identify derecho events utilizing archived data and wind reports (after BM98)

\begin{tabular}{|c|c|}
\hline JH87 & BM98 \\
\hline $\begin{array}{l}\text { There must be a concentrated } \\
\text { area of convectively induced } \\
\text { wind gusts greater than } \\
25 \mathrm{~m} \mathrm{~s}^{-1} \text { that has a major axis } \\
\text { length of at least } 400 \mathrm{~km}\end{array}$ & Same \\
\hline $\begin{array}{l}\text { The wind reports must have } \\
\text { chronological progression. }\end{array}$ & Same \\
\hline $\begin{array}{l}\text { No more than } 3 \text { h can elapse } \\
\text { between successive wind } \\
\text { reports }\end{array}$ & $\begin{array}{l}\text { No more than } 2 \text { h can } \\
\text { elapse between } \\
\text { successive wind reports }\end{array}$ \\
\hline $\begin{array}{l}\text { There must be at least } 3 \\
\text { reports of either } \mathrm{F} 1 \text { damage } \\
\text { or wind gusts greater than } \\
34 \mathrm{~m} \mathrm{~s}^{-1} \text { separated by at } \\
\text { least } 64 \mathrm{~km}\end{array}$ & Not used \\
\hline $\begin{array}{l}\text { The associated MCS must } \\
\text { have temporal and spatial } \\
\text { continuity }\end{array}$ & $\begin{array}{l}\text { The associated MCS must } \\
\text { have temporal and spatial } \\
\text { continuity with no more } \\
\text { than } 2^{\circ} \text { of latitude or } \\
\text { longitude separating } \\
\text { successive wind reports }\end{array}$ \\
\hline $\begin{array}{l}\text { Multiple swaths of damage } \\
\text { must be part of the same } \\
\text { MCS as indicated by } \\
\text { National Weather Service } \\
\text { radar summaries }\end{array}$ & $\begin{array}{l}\text { Multiple swaths of } \\
\text { damage must be part of } \\
\text { the same MCS as seen by } \\
\text { temporally mapping the } \\
\text { wind reports of each event }\end{array}$ \\
\hline
\end{tabular}

Composite reflectivity values obtained from radar archives were also examined to ensure convective characteristics of many cool-season (September-February) DMCSs. These images were obtained from the National Climate Data Center's (NCDC) on-line radar archive (available at http://lwf.ncdc.noaa.gov/oa/ radar/radardata.html).

Data from the NCEP/NCAR reanalysis were used to reconstruct the $500 \mathrm{hPa}$ environment during months of DMCS activity. The reanalysis uses a frozen state-ofthe-art global data assimilation system and a database as complete as possible to eliminate perceived climate jumps and discontinuities associated with analysis procedure changes. Kalnay et al. (1996) reviewed these, listing geopotential height as an 'A' field, which is defined as a variable strongly influenced by observed data and, hence, is in the most reliable class. These data were obtained from the Climate Diagnostics Center (available at http://www.cdc.noaa.gov/cdc/ data.nmc.reanalysis.html). Daily Weather Maps: Weekly Series, published by the Climate Prediction Center, were also consulted in order to determine the location of surface features during several DMCS episodes.

A primary method chosen to examine the temporal and spatial distributions of DMCS events focused on the identification of individual corridors that separated derechos into groups of damage coverage, location and movement. Specifically, a corridor is defined when 4 or more events with similar spatial and temporal characteristics occur in a season (Trenberth 1983, BM98). To assess temporal characteristics, 3 seasons are defined: (1) spring season-March-May; (2) summer seasonJune-August; and (3) cool season-September-February. These are defined based on evidence that suggests there are seasonal differences in processes that initiate DMCSs (Bentley et al. 2000). JH87 defined 2 primary structures of DMCSs: serial and progressive. A serial DMCS is dynamically induced, and it is associated with squall lines produced by strong synoptic-scale low-pressure systems. These DMCSs can occur at any time of the year, but are primarily cool-season events (Johns 1993). Progressive DMCSs typically initiate in environments of strong low-level thermodynamic instability and weaker dynamic forcing for upward vertical motion. They usually occur during the warm season.

\section{RESULTS}

\subsection{6-2000 DMCS distribution}

A total of 118 DMCSs were identified from 1996 to 2000. Contrary to previous investigations, May proved to be the most active month during the $5 \mathrm{yr}$ period 


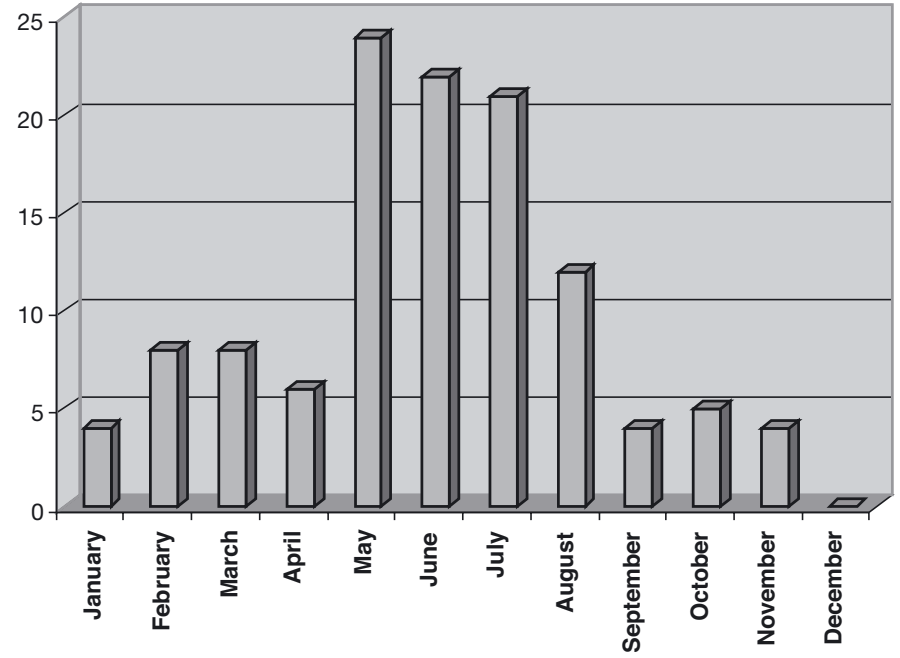

Fig. 1. Total number of identified derechos occurring per month, 1996-2000

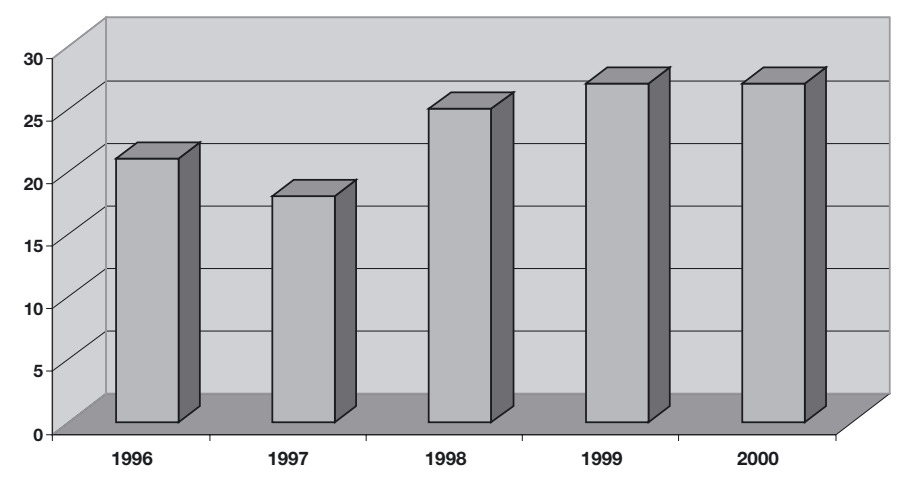

Fig. 2. Annual frequency of derechos identified, 1996-2000
(Fig. 1; JH87, BM98). Weak secondary peaks are evident in February and October. Consultation of the daily synoptic weather maps indicate that the coolseason events are associated with vigorous mid-latitude cyclones characteristic of the autumn and latewinter seasons. The most active years, 1999 and 2000, experienced 27 DMCSs, with 20,17, and 24 occurring in 1996, 1997, and 1998 respectively (Fig. 2).

A northward displacement of the primary region of derecho activity from the southern Plains in 1986-1995 to the Midwest during 1996-2000 is evident in the $5 \mathrm{yr}$ distributions of contoured DMCS damage reports (Fig. 3). A prominent feature includes the maximum of DMCS activity over the upper Mississippi River valley. The location and orientation of the primary region of DMCS activity suggest an active axis of NW-flow severe weather outbreaks during the $5 \mathrm{yr}$ period (Johns 1984). Other shifts in the DMCS distribution include the abundance of activity over the Southeast during 1996-2000. This is particularly evident in western Tennessee, where very little activity occurred during the previous $10 \mathrm{yr}$. Another maximum is centred over the Ohio Valley, consistent with the 1986-1995 investigation.

Analysis indicates the existence of 3 new corridors that were not identified in the 1986-1995 climatology. An isolated, cool-season, Midwest corridor contains 8 events (Fig. 4). Long tracks, long duration (on average $12.7 \mathrm{~h}$ ), and NE movement characterize these events. Surface analysis reveals that 5 of the 8 events initiated within the warm sector and along a strong cold front emanating from a strong mid-latitude cyclone and during the period from 22:00 to 10:00 h UTC. Another new

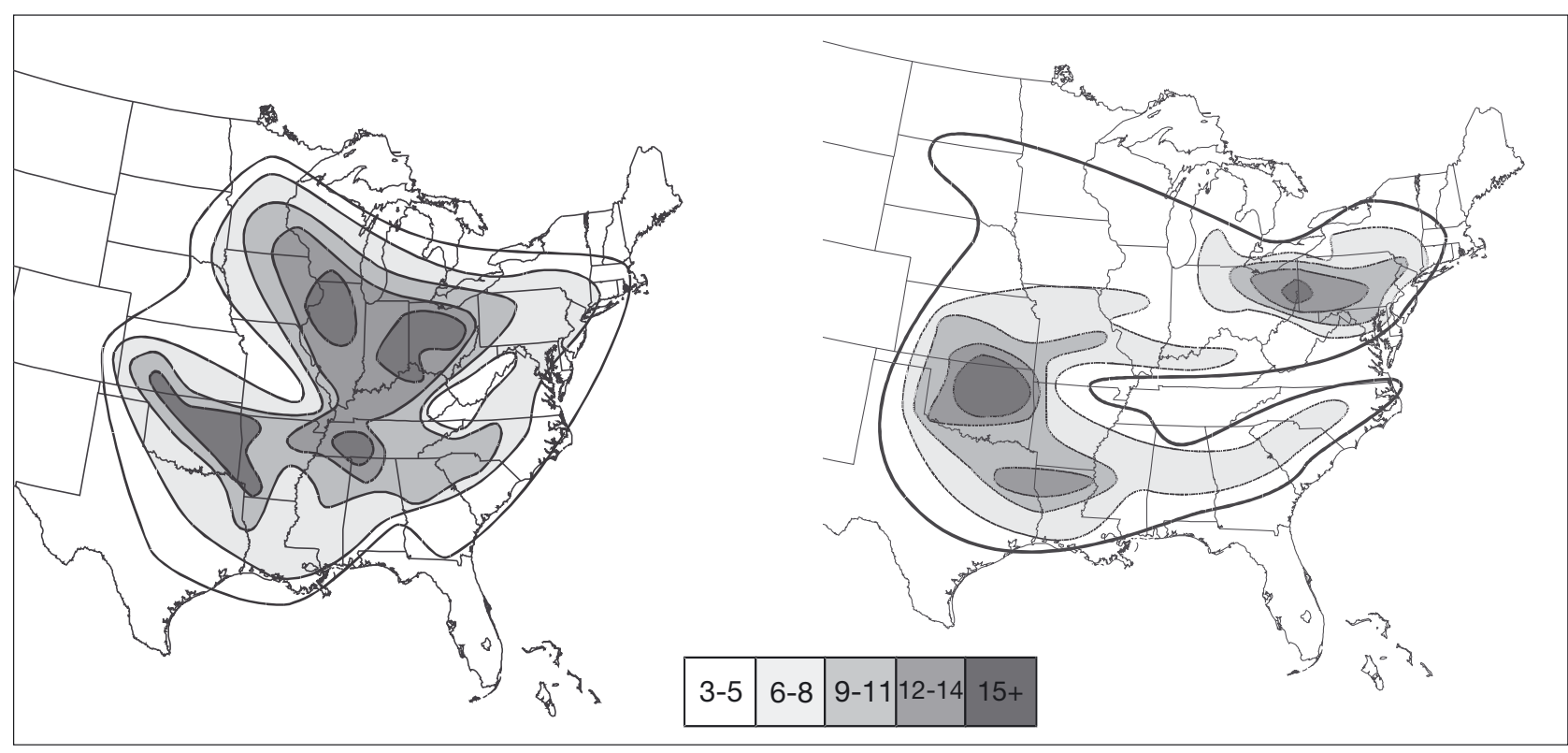

Fig. 3. Total number of derechos occurring during the entire year, (a) 1996-2000 and (b) 1986-1995 (BM98) 


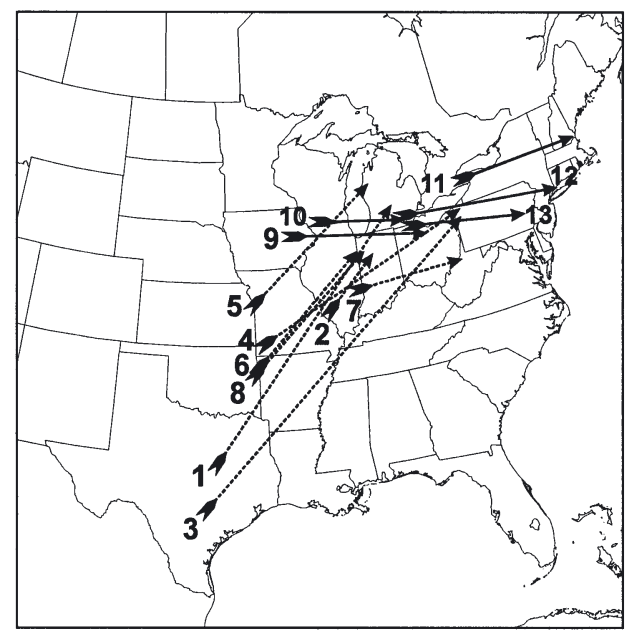

\begin{tabular}{cr|cr} 
Event & \multicolumn{1}{c|}{ Date } & Event & \multicolumn{1}{c}{ Date } \\
\hline 1 & $1 / 18 / 96$ & 8 & $1 / 3 / 00$ \\
2 & $10 / 18 / 96$ & 9 & $10 / 29 / 96$ \\
3 & $11 / 7 / 96$ & 10 & $9 / 19 / 97$ \\
4 & $11 / 10 / 98$ & 11 & $9 / 7 / 98$ \\
5 & $2 / 11 / 99$ & 12 & $9 / 7 / 98$ \\
6 & $2 / 11 / 99$ & 13 & $10 / 13 / 99$ \\
7 & $9 / 20 / 00$ & & \\
\hline
\end{tabular}

Fig. 4. Individual event tracks and initiation dates for the cool-season Midwest corridor (dashed) and the cool-season Great Lakes corridor (solid), 1996-2000

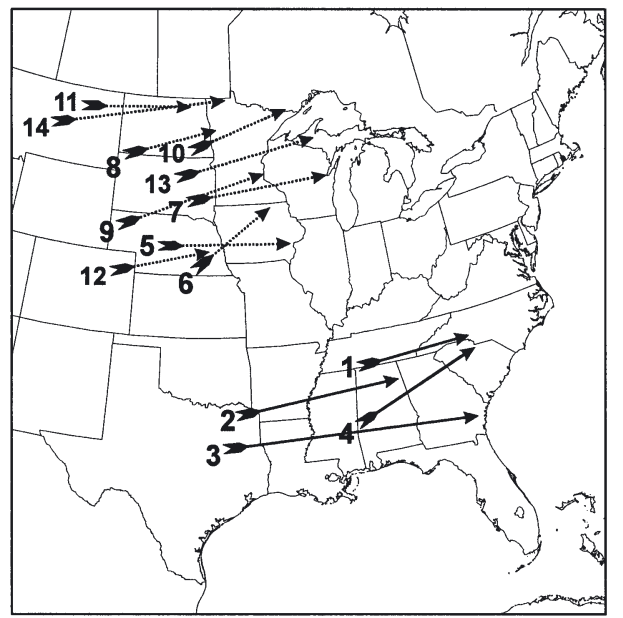

\begin{tabular}{cr|cr} 
Event & \multicolumn{1}{c|}{ Date } & Event & \multicolumn{1}{l}{ Date } \\
\hline 1 & $7 / 4 / 97$ & 8 & $6 / 26 / 99$ \\
2 & $6 / 5 / 98$ & 9 & $7 / 3 / 99$ \\
3 & $6 / 5 / 98$ & 10 & $7 / 4 / 99$ \\
4 & $6 / 16 / 98$ & 11 & $7 / 22 / 99$ \\
5 & $6 / 2 / 97$ & 12 & $7 / 23 / 99$ \\
6 & $6 / 24 / 98$ & 13 & $8 / 18 / 99$ \\
7 & $6 / 25 / 98$ & 14 & $8 / 11 / 00$ \\
\hline
\end{tabular}

Fig. 5. Individual event tracks and initiation dates for the summer-season Southeast corridor (solid) and the summer-season, NE-moving central Plains corridor (dashed), 1996-2000

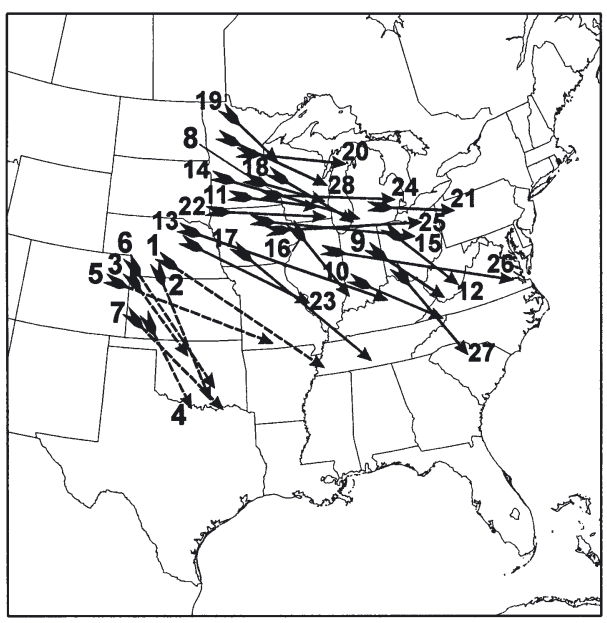

\begin{tabular}{cr|cr} 
Event & \multicolumn{1}{c|}{ Date } & Event & \multicolumn{1}{l}{ Date } \\
\hline 1 & $7 / 22 / 96$ & 15 & $8 / 24 / 98$ \\
2 & $8 / 2 / 96$ & 16 & $6 / 1 / 99$ \\
3 & $8 / 22 / 97$ & 17 & $6 / 4 / 99$ \\
4 & $8 / 22 / 97$ & 18 & $7 / 8 / 99$ \\
5 & $7 / 1 / 99$ & 19 & $7 / 25 / 99$ \\
6 & $7 / 21 / 00$ & 20 & $7 / 30 / 99$ \\
7 & $7 / 22 / 00$ & 21 & $7 / 31 / 99$ \\
8 & $6 / 29 / 96$ & 22 & $6 / 1 / 00$ \\
9 & $7 / 2 / 97$ & 23 & $6 / 25 / 00$ \\
10 & $6 / 22 / 98$ & 24 & $7 / 10 / 00$ \\
11 & $6 / 27 / 98$ & 25 & $8 / 6 / 00$ \\
12 & $6 / 27 / 98$ & 26 & $8 / 9 / 00$ \\
13 & $6 / 29 / 98$ & 27 & $8 / 9 / 00$ \\
14 & $7 / 20 / 98$ & 28 & $8 / 14 / 00$
\end{tabular}

Fig. 6. Individual event tracks and initiation dates for the summer-season, northern-tier corridor (solid) and the summer-season, southward-burst corridor (dashed), 1996-2000 


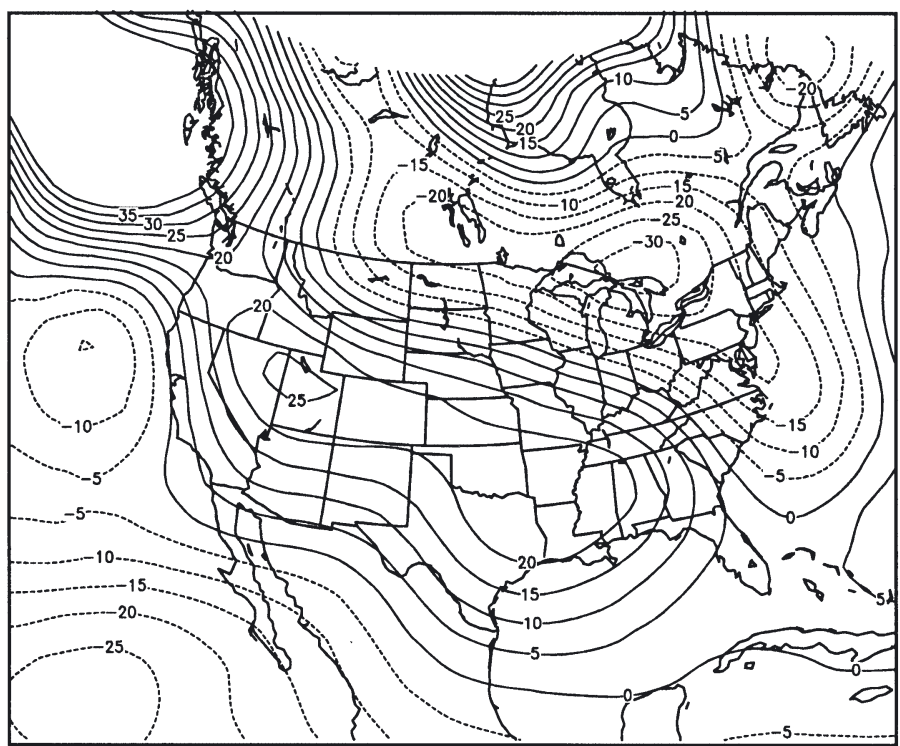

Fig. 7. $500 \mathrm{hPa}$ height anomaly event composite using a climatological mean of 1968-1996 for 9 northern-tier DMCSs occurring in June-August 2000

cool-season corridor is evident in the Great Lakes region (Fig. 4). These events are essentially eastward movers and occur early in the cool season (September and October). Analysis of local climatological data from stations in close proximity to the initiation of DMCSs in this corridor reveal the presence of surface temperatures $6^{\circ} \mathrm{C}$ above normal at several stations prior to DMCS initiation. Surface analyses also indicate that these events developed in the warm sector of strong mid-latitude cyclones, where sufficient instability and strong vertical wind shear were present. The summer season also contained a new corridor during 1996-2000 located in the Southeast (Fig. 5). These DMCSs moved toward the east to northeast and also occurred early in the summer (June and early July). They are similar in duration, direction of movement, and initiation time to spring-season Southeast events (BM98).

\subsection{Comparisons between the 1986-1995 and 1996-2000 DMCS distributions}

Nearly $80 \%$ of DMCSs in this 5 yr update occurred within 14 activity corridors, 11 of which were identified in the $10 \mathrm{yr}$ climatology (BM98). Each corridor defined in the 1986-1995 climatology (BM98) was represented in the most recent 5 yr period.

The most active summertime corridor in this investigation is the southeastward moving northern-tier corridor along the climatological axis of
NW-flow severe weather outbreaks (Fig. 6; Johns 1984). From 1996 to 2000, 21 DMCSs developed, with one-third occurring in 2000, a summer characterized by a large, persistent warm-core anticyclone over the central and western US that created a favorable mid-level shear and low-level thermodynamic environment across the northern Plains and upper Midwest (Fig. 7). Furthermore, this is a region characterized by the mean location of the polar front oriented northwest to southeast through the northern tier of the US (Johns 1984). Seventeen of the 21 northern tier events identified initiated between 16:00 and 20:00 h UTC when convective available potential energy typically reaches a diurnal maximum.

The second most active summer-season corridor during 1996-2000 is the northeastward-moving central Plains events (Fig. 5; BM98). As was found in the $10 \mathrm{yr}$ study, these are primarily early summer-season events, with $80 \%$ (8 of 10) occurring in June and July. Eighty percent of these events also initiated between 22:00 and 04:00 $\mathrm{h}$ UTC, indicative of typical summer-season nocturnal mesoscale convective complex development (Maddox 1983). Synoptic analysis shows that these events initiate along the eastern flank of a $500 \mathrm{hPa}$ trough over the western US (Fig. 8). When the corresponding eastern US ridge deamplifies and builds westward, derecho activity shifts to the northern-tier corridor. Therefore, an active NEmoving, central-Plains DMCS corridor may be a precursor to northern-tier DMCS (NW flow) activity under a

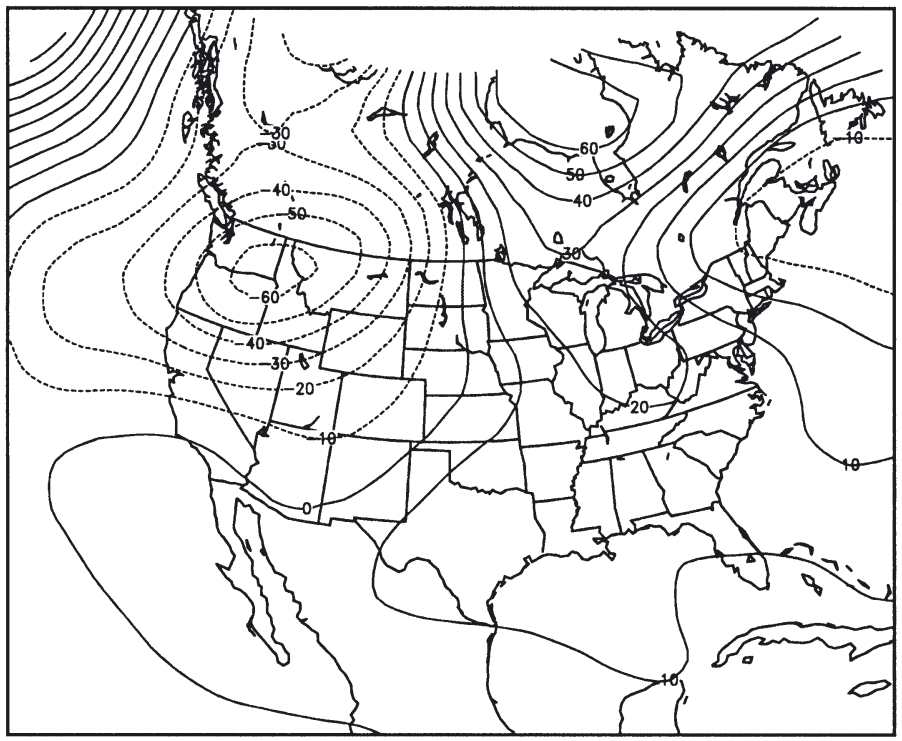

Fig. 8. $500 \mathrm{hPa}$ height anomaly event composite using a climatological mean of 1968-1996 for 14 summer-season, northeastmoving, central-Plains DMCSs, 1996-2000 


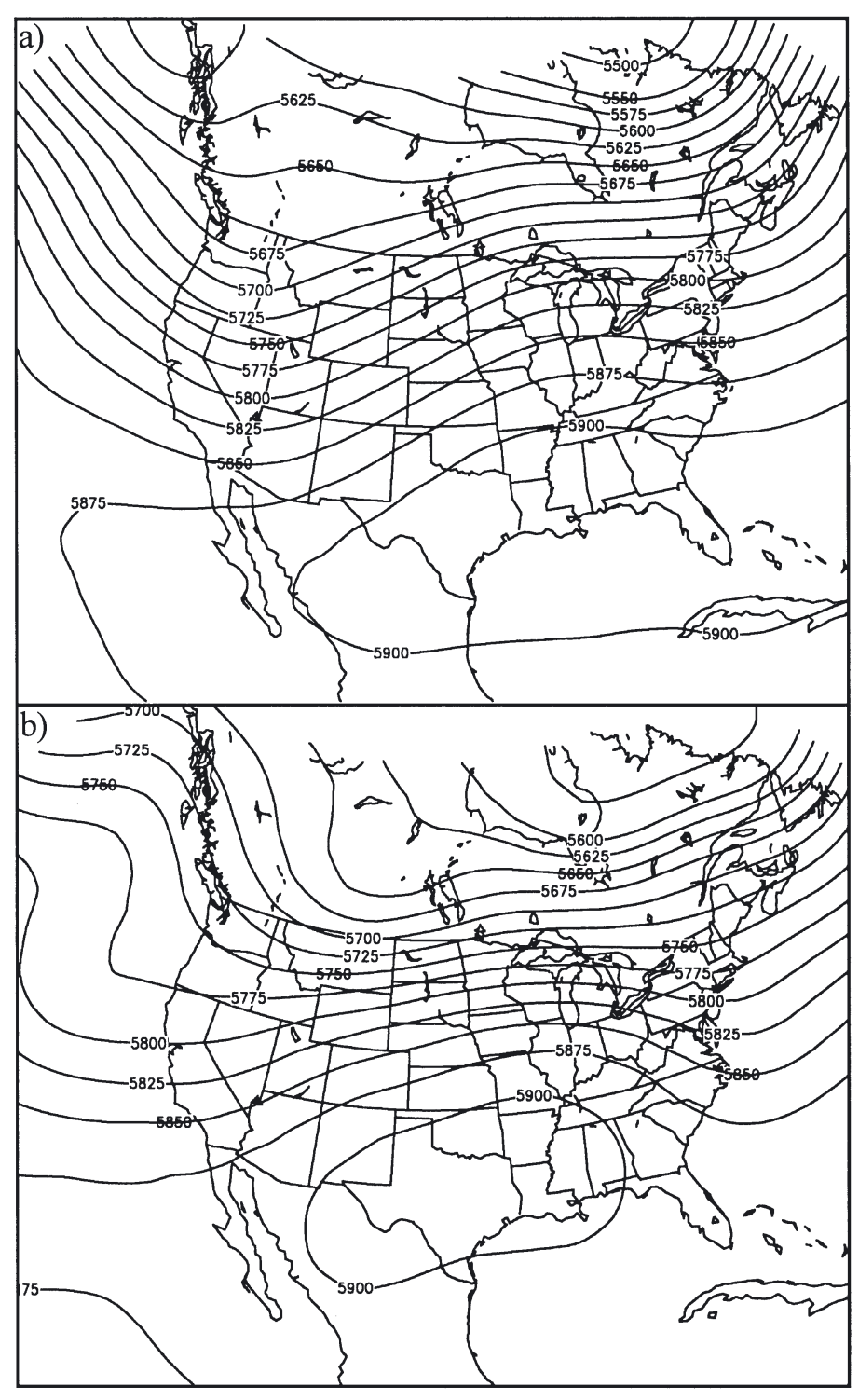

Fig. 9. (a) $500 \mathrm{hPa}$ height (dm) event composite for 14 summer-season, NE-moving, central-Plains DMCSs that preceded 11 northern tier DMCSs, 1986-2000. (b) $500 \mathrm{hPa}$ height event composite for 11 summer-season, northern-tier DMCS that succeeded the $14 \mathrm{NE}$-moving, central-Plains DMCSs, 1986-2000

$500 \mathrm{hPa}$ ridge that is building westward (Fig. 9). This shift in DMCS activity primarily occurred during the 1998 and 1999 summer seasons and will be detailed in the following section.

Another summertime corridor is located in the central and southern Plains and is associated with southward-burst DMCSs (Fig. 6; Porter et al. 1955, BM98). Southward-burst DMCSs are those that occur primarily in the southern Plains and, once developed, move nearly due south, sometimes into the Gulf of Mexico (Porter et al. 1955). Results from the 10 yr climatology indicated southward-burst DMCSs are among the longest duration derechos of the summer season. The 1996-2000 events' average sustenance of $8.7 \mathrm{~h}$ proved to be second only in duration to the new Southeast corridor DMCSs (9 h). Much like the events in the $10 \mathrm{yr}$ study, those in the $5 \mathrm{yr}$ period favored overnight and early morning development. Additionally, this corridor contained a high number of August derechos $(43 \%$ or 3 of 7$)$. During the entire $15 \mathrm{yr}$, nearly $35 \%$ (7 of 20) of southward-burst DMCSs occurred in August, a higher percentage than any other summer-season corridor.

The spring season consisted of 5 corridors, all of which were identified in the 1986-1995 study (BM98). Interestingly, there was no monthly increase in derecho activity apparent in the months of March and April during the $5 \mathrm{yr}$ study (Fig. 1). A steady increase in activity was noted for these successive months in the 1986-1995 climatology. Eight derechos occurred in the month of March, dropping to only 6 in April. However, the less active early spring yielded to a very active month of May (23 derechos).

Contrary to the $10 \mathrm{yr}$ study, the most active spring-season corridor was not the NE-moving, southern-Plains corridor (BM98). Only 4 derechos occurred in this region throughout the $5 \mathrm{yr}$ period. The Southeast corridor proved to be most active (Fig. 10). One would expect derecho activity in the Southeast to be most prominent during the cool and early spring seasons, when the region experiences strong cold frontal passages (Bentley \& Mote 2000). As expected, 4 of the 7 Southeast DMCSs occurred during the month of March and first week of April, a feature consistent with the previous $10 \mathrm{yr}$.

As is the case for the summer season, an Ohio Valley corridor exists for the spring season (Fig. 10). Similarities in their duration and initiation times (no preferred initiation time) are consistent with summer-season Ohio-Valley DMCS events.

From 1996-2000, 3 spring season DMCS events occurred in a Northeast corridor defined by BM98 (Fig. 10). These late afternoon events had the shortest average duration of events in any corridor $(5.2 \mathrm{~h})$. Due to the northern location of the corridor, it is not surprising that these are late-spring-season events, as all 7 events compiled from both studies occurred in April and May.

The cool season is distinguished by its relative frequency minimum in derecho activity. The cool season accounted for $18 \%$ (20 of 112) of the derechos in 1986-1995. The 1996-2000 period was shown to have 


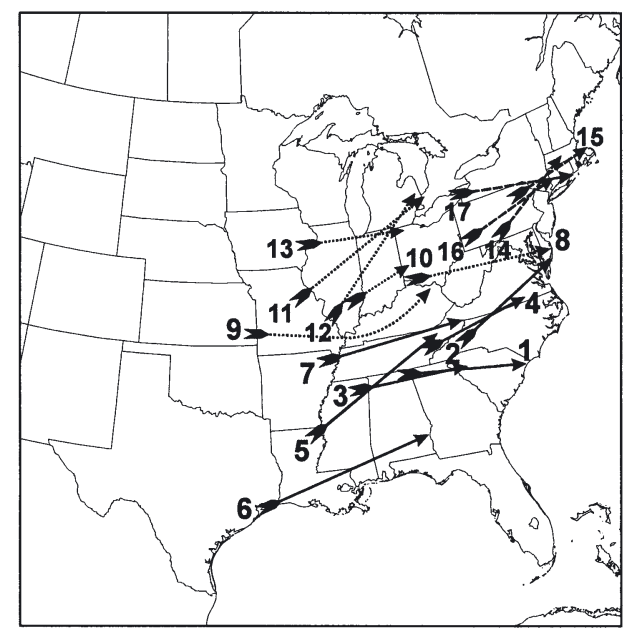

\begin{tabular}{cr|cr} 
Event & \multicolumn{1}{l|}{ Date } & Event & \multicolumn{1}{l}{ Date } \\
\hline 1 & $3 / 14 / 96$ & 10 & $3 / 28 / 97$ \\
2 & $5 / 11 / 96$ & 11 & $5 / 9 / 00$ \\
3 & $3 / 5 / 97$ & 12 & $5 / 9 / 00$ \\
4 & $3 / 5 / 97$ & 13 & $5 / 18 / 00$ \\
5 & $5 / 5 / 99$ & 14 & $5 / 11 / 96$ \\
6 & $4 / 3 / 00$ & 15 & $5 / 21 / 96$ \\
7 & $5 / 27 / 00$ & 16 & $5 / 19 / 97$ \\
8 & $5 / 4 / 96$ & 17 & $4 / 20 / 00$ \\
9 & $5 / 5 / 96$ & & \\
\hline
\end{tabular}

Fig. 10. Individual event tracks and initiation dates for the spring-season Southeast corridor (solid), spring-season Ohio-Valley corridor (short-dashed) and the spring-season Northeast corridor (dashed), 1996-2000

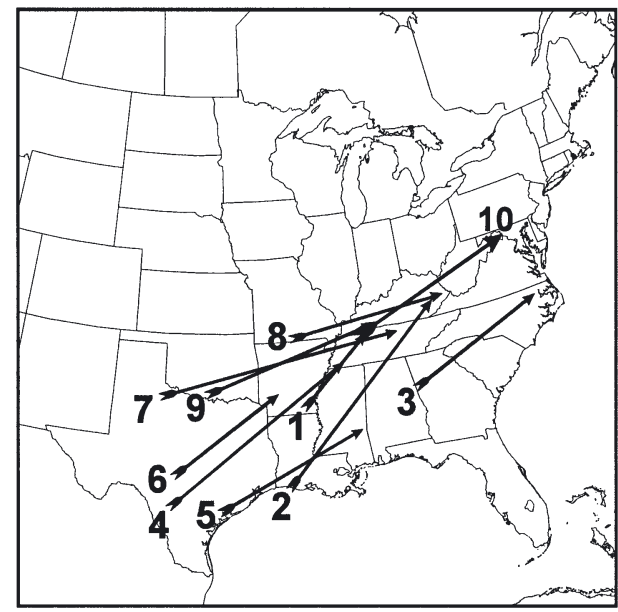

\begin{tabular}{cr|cr} 
Event & Date & Event & \multicolumn{1}{c}{ Date } \\
\hline 1 & $10 / 18 / 96$ & 6 & $2 / 25 / 98$ \\
2 & $2 / 21 / 97$ & 7 & $11 / 10 / 98$ \\
3 & $2 / 21 / 97$ & 8 & $1 / 17 / 99$ \\
4 & $2 / 10 / 98$ & 9 & $2 / 6 / 99$ \\
5 & $2 / 26 / 98$ & 10 & $11 / 9 / 00$ \\
\hline
\end{tabular}

Fig. 11. Individual event tracks and initiation dates for the cool-season Southeast corridor, 1996-2000

a slightly more active winter season, with the development of $20 \%$ of all DMCSs. In the $10 \mathrm{yr}$ study, a secondary maximum of activity occurred during the month of November, many of which occurred along the Gulf Coast and Atlantic Seaboard. The 5 yr period contained 2 weak maxima in the months of October and February. The Southeast corridor remained very active from 1996-2000, with 10 events developing during the period (Fig. 11). Their long duration of $10.5 \mathrm{~h}$ is consistent with the 1986-1995 events (BM98); however, the 5 yr study shows these events to prefer afternoon and evening development rather than morning development. It is expected that cold-season events of most corridors may not have predictable diurnal patterns of development, due to their dependence on larger-scale dynamic forcing (Bentley \& Mote 2000).

\subsection{Cumulative 15 yr findings}

Previous investigations have related the increase in derechos to more aggressive storm-report verification and shifts in population density throughout the eastern US (Johns \& Evans 2000). Due to the distinct increase in derecho activity in the northern Plains during the 15 yr period, evidence suggests that climatological as well as non-climatological factors contribute to the shifts in the DMCS distribution (Weiss \& Vescio 1998, Johns \& Evans 2000). For example, 7 events were identified in the NW-flow corridor throughout the northern Plains during 1986-1992. From 1993 to 2000, 32 DMCS events occurred in the same region. Likewise, 7 events were identified in the southward-burst corridor of the central and southern Plains during 1986-1992, while 
13 events occurred from 1993 to 2000. During the last 25 yr severe convective wind reports have increased greatly throughout the eastern US; however, most of this increase has occurred in the southern Plains, a region exhibiting only modest increases in DMCS activity (Johns \& Evans 2000). Therefore, increases and shifts in population density and the reporting of severe convective wind gusts across the eastern US
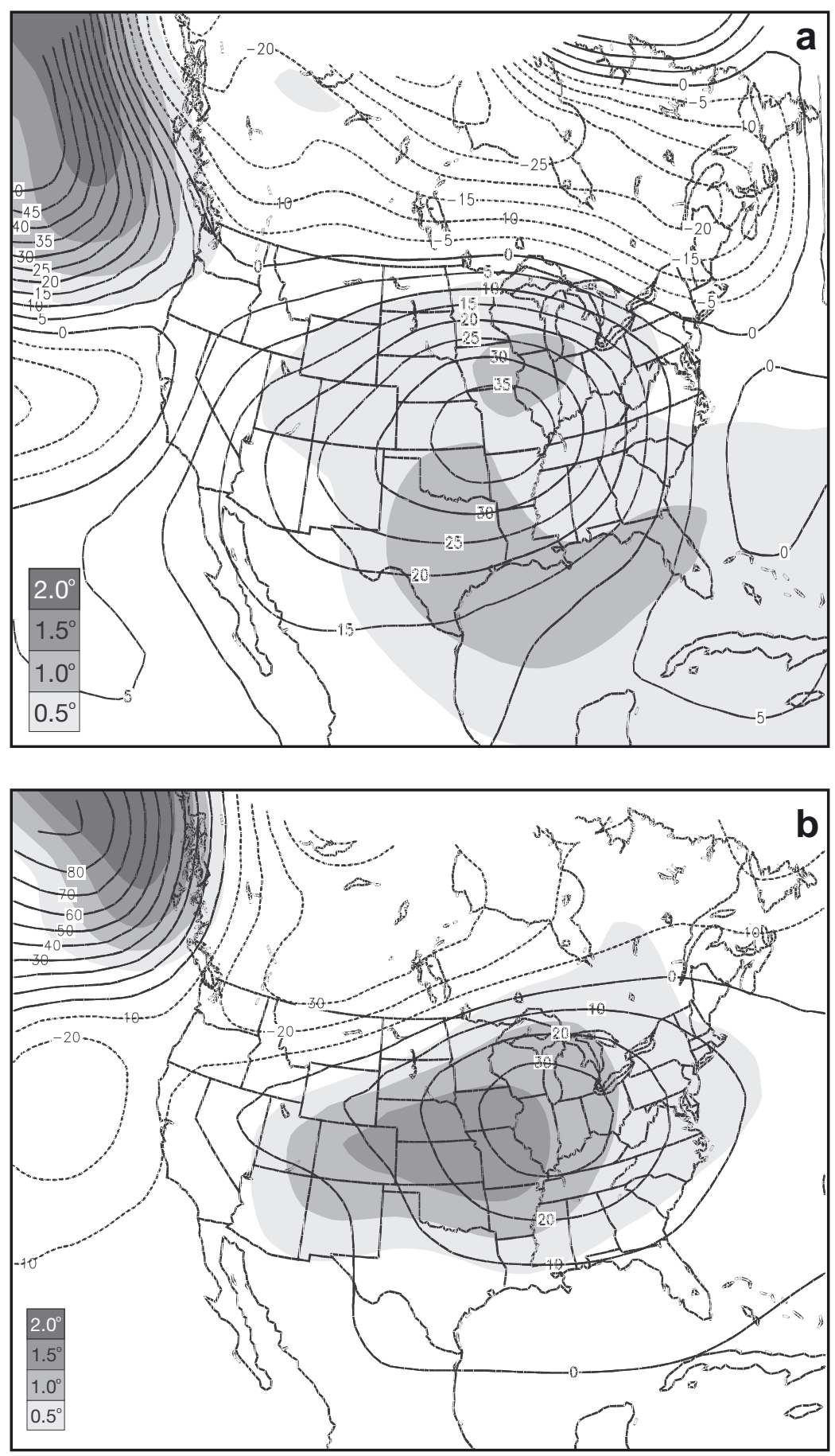

Fig. 12. $500 \mathrm{hPa}$ height (solid: positive; dashed: negative) and air-temperature $\left({ }^{\circ} \mathrm{C}\right.$, shaded) anomalies using a climatological mean of 1968-1996 for (a) July 1980, when 10 DMCS events were identified (JH87), and (b) July 1999, when 11 derechos were identified cannot fully explain the observed increase and shifts in the spatial distribution of derechos, especially the increase in northern-tier events. It appears changes in the location of favourable synoptic environments leading to the development of derecho activity, particularly during the warm season in the Great Plains, control the DMCS geographical and frequency distributions. This becomes even more evident when comparing the $500 \mathrm{hPa}$ height anomalies during months of extreme DMCS activity (Fig. 12). One particularly favourable synoptic environment for DMCS formation in the central and northern Plains through the Ohio Valley is the development of a persistent warm-core anticyclone in the east-central US (Fig. 12). This warm-season pattern typically facilitates under-running of warm unstable air around the periphery of the ridge and 'ring of fire' MCS development ensues (Bosart et al. 1999). It also appears that DMCSs favour an anomalously strong $500 \mathrm{hPa}$ height gradient on the northern and western edges of this strong anticyclone (Figs. $7 \& 12$ ).

Since the synoptic environment is an important control in the spatial and temporal distributions of summerseason derechos, it is useful to examine the temporal grouping of DMCSs within corridors and also assess the utility of using the NE-moving, central-Plains events as a precursor to activation of the northern-tier (NW flow) corridor. The latter relationship is due to the presumption that oftentimes a low-amplitude $500 \mathrm{hPa}$ ridge present during NE-moving, centralPlains events will later amplify, build westward and help activate the northern-tier derecho corridor.

Of 38 northern-tier DMCSs identified over $15 \mathrm{yr}, 19$ of them occurred within 7 to $8 \mathrm{~d}$ groupings (Table 2). NW-flow severe weather outbreaks, of which derechos in this corridor are a subset, were also found to occur in 
Table 2. Initiation dates for northern tier DMCSs that occurred in groups during 1986-2000

\begin{tabular}{|c|c|}
\hline Group & Event date \\
\hline 1 & $\begin{array}{r}2 \text { Jul } 1992 \\
\text { 10 Jul } 1992\end{array}$ \\
\hline 2 & $\begin{array}{l}\text { 12 Jul } 1995 \\
\text { 13 Jul } 1995 \\
\text { 14 Jul } 1995 \\
\text { 15 Jul } 1995\end{array}$ \\
\hline 3 & $\begin{array}{l}\text { 22 Jun } 1998 \\
\text { 27 Jun } 1998 \\
\text { 27 Jun } 1998 \\
\text { 29 Jun } 1998\end{array}$ \\
\hline 4 & $\begin{array}{l}1 \text { Jun } 1999 \\
\text { 4 Jun } 1999\end{array}$ \\
\hline 5 & $\begin{array}{l}\text { 25 Jul } 1999 \\
\text { 30 Jul } 1999 \\
\text { 31 Jul } 1999\end{array}$ \\
\hline 6 & $\begin{array}{r}6 \text { Aug } 2000 \\
9 \text { Aug } 2000 \\
9 \text { Aug } 2000 \\
14 \text { Aug } 2000\end{array}$ \\
\hline
\end{tabular}

Table 3. Initiation dates for northeast moving central Plains DMCSs that occurred in groups during 1986-2000

\begin{tabular}{|lr|}
\hline Group & Event date \\
\hline 1 & 3 Jul 1987 \\
& 11 Jul 1987 \\
2 & 12 Jul 1987 \\
& 4 Jun 1995 \\
3 & 8 Jun 1995 \\
& 24 Jun 1998 \\
4 & 25 Jun 1998 \\
5 & 3 Jul 1999 \\
& 4 Jul 1999 \\
& 22 Jul 1999 \\
\hline
\end{tabular}

series (Johns 1984). During extremely active years (i.e. $1995,1998,1999,2000), 65 \%$ of the northern-tier DMCSs occurred as groups or 'families'. For NEmoving, central-Plains DMCSs, 11 of 21 events occurred within groups (Table 3). During an active year (1999) 4 of 5 events occurred within 2 groups of 2 derechos per group. Polar mesoscale lows, which in many respects are the cold-season, oceanic equivalent of MCCs have also been found to occur in groups or families (Carleton \& Song 1997). Finally, southwardburst DMCSs appeared to be less likely to occur in groups or families, with only 7 out of 20 events exhibiting this pattern (Table 4).
Table 4. Initiation dates for southward burst DMCSs that occurred in groups during 1986-2000

\begin{tabular}{|lr|}
\hline Group & Event date \\
\hline 1 & 5 Jun 1994 \\
& 7 Jun 1994 \\
& 9 Jun 1994 \\
2 & 22 Aug 1997 \\
& 22 Aug 1997 \\
& 21 Jul 2000 \\
& 22 Jul 2000 \\
\hline
\end{tabular}

NE-moving, central-Plains DMCSs were also found to be a useful precursor to the development of northern-tier events. Of the 38 northern-tier DMCSs, 11 occurred within $8 \mathrm{~d}$ of a NE-moving, central-Plains event. In fact, 10 of the 11 occurred within $3 \mathrm{~d}$ of a northeastward-moving, central-Plains DMCS. In the extremely active years listed above, $42 \%$ of the northern-tier DMCSs occurred no later than $3 \mathrm{~d}$ after a NEmoving, central-Plains derecho. Additionally, only 7 of 21 NE-moving, central-Plains DMCSs occurred without being followed by a northern-tier event.

Evidence suggests that the strength of these relationships, especially among northern-tier and NEmoving, central-Plains DMCSs, is due to the importance of the location and intensity of synoptic-scale warm-core anticyclones (Fig. 9; Johns 1984, Bosart et al. 1999, Bentley et al. 2000). The development of favourable conditions along the periphery of these features often leads to successive DMCS development along one of the identified activity corridors.

Monthly analysis of the $15 \mathrm{yr}$ climatology as a whole reveals a steady increase in activity from January until July (Fig. 13). DMCS activity begins in the Southeast and Midwest corridors early in the year and spreads into the southern-Plains corridor by February and March. A distinct increase takes place from April to May as the NE-moving, central-Plains and northerntier derechos become active, and then a decrease in DMCS activity occurs from July to August. May through July is very active, as $54 \%$ (125 of 230) of DMCSs occur during these months. A weak secondary peak in October and November replaced the lull in activity in September. The Atlantic-Seaboard, Midwest, and Great-Lakes corridors contribute to most of the secondary maximum this time of year. December is the quietest month, as only 4 events were identified. Analysis of derecho activity over the $15 \mathrm{yr}$ period also identified favored regions of DMCSs (Fig. 14). Maxima exist in the central and southern Plains, with the northern Plains and Ohio Valley also exhibiting peaks in DMCSs occurrence. 


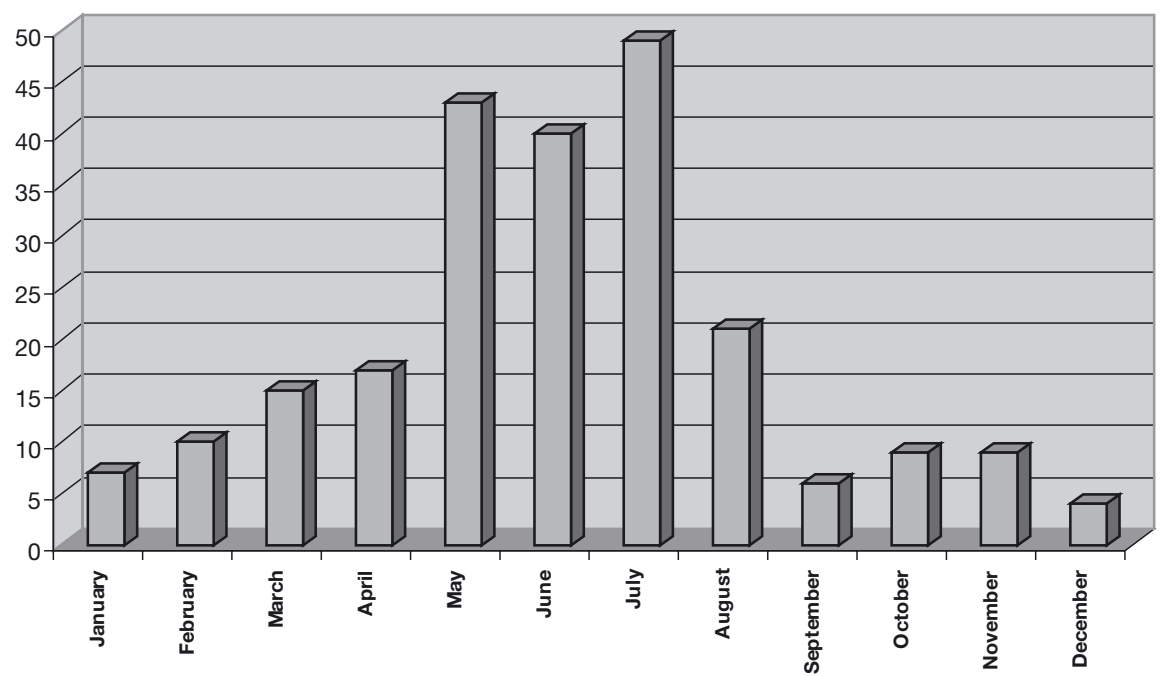

Fig. 13. Total number of identified derechos occurring during each month, 1986-2000

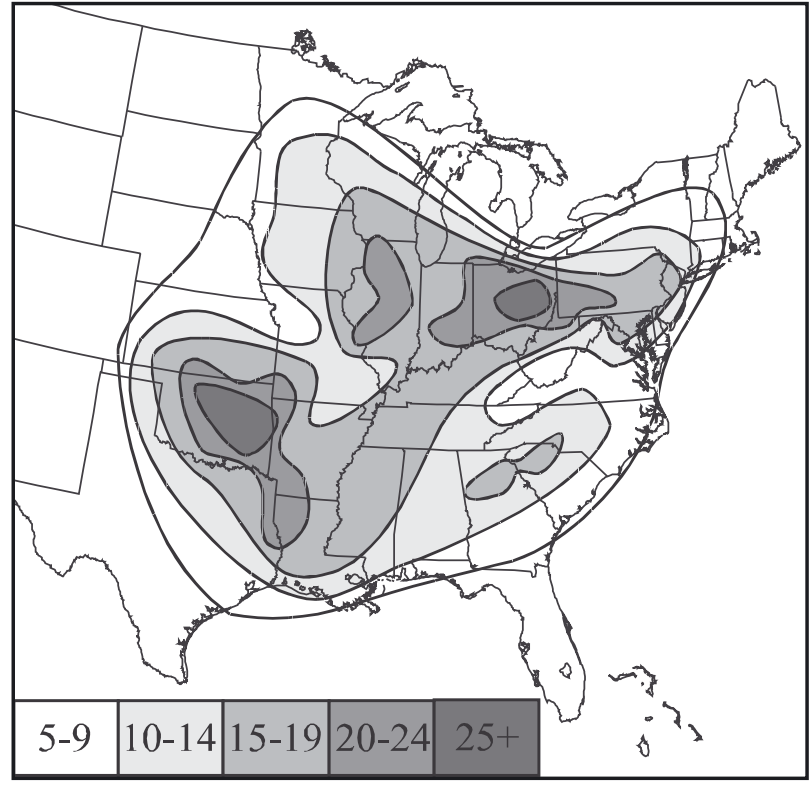

Fig. 14. Total number of derechos occurring during the entire year, 1986-2000

\section{CONCLUSIONS}

Five years (1996-2000) of severe-wind and damagereport data were examined in order to temporally and spatially identify long-lived severe convective windstorms known as derechos. The current investigation serves as an update to a 10 yr climatology of DMCSs performed by BM98. Many important consistencies and additions were noted in comparing this update to BM98; these include the following points:
- The emergence of the northern-tier corridor, a prominent axis of NW flow in 1996 to 2000, as the dominant activity corridor in the climatology.

- The apparent occurrence of DMCSs in 'families' throughout the $15 \mathrm{yr}$ period, with more than half of the northern-tier, SE-moving and NE-moving, central-Plains DMCSs occurring in groups.

- The NE-moving, central-Plains DMCSs appear to be precursors to northern-tier DMCSs. In fact, 11 of 38 northern-tier DMCS events succeeded a NEmoving, central-Plains event by $8 \mathrm{~d}$ or less. Additionally, only 7 of 21 NE-moving, central-Plains DMCSs occurred without being followed by a northern-tier event. This finding suggests that NE-moving, central-Plains events manifest themselves in the earlier stages of a low-amplitude warm-core anticyclone when the flow aloft is southwesterly over the central Plains. As the anticyclone shifts northward and amplifies, the periphery of the ridge, which is characterized by NW flow aloft and convergence associated with the polar front at the surface, encompasses the northern-tier US region activating this derecho corridor.

- Three new activity corridors also became apparent during the $5 \mathrm{yr}$ update that were not evident in the previous $10 \mathrm{yr}$ investigation. These included a coolseason, NE-moving, Midwest corridor, an early coolseason, Great-Lakes corridor, and a summer-season Southeast corridor.

- May, June and July remain the most active months for derecho activity, with a relative maximum in activity occurring through the northern-tier US, while the fewest number of derechos occur in December and January. A secondary maximum in 
derecho activity is manifested in the months of October and November, with DMCSs developing and moving through the Gulf-Coast and AtlanticSeaboard regions.

- There appears to be an increase in annual derecho activity throughout the 15 yr period, especially from the early 1990s to 2000. As mentioned before, these changes appear to be primarily due to climatological factors, not shifts in population.

This investigation of derecho activity does not represent a 'complete climatology' per se, but represents an ongoing attempt to properly and accurately capture the genuine character and long-term variation of derechos. The accomplishment of this will require examination of many more years of derecho activity. In doing so, general consistencies and commonalities among derecho-activity corridors and their associated synoptic patterns will be further identified.

Acknowledgements. The authors wish to thank Dr. Chip Konrad of the University of North Carolina-Chapel Hill, 2 anonymous reviewers, and Dr. Robert E. Davis (editor) for insightful reviews and many constructive revisions to this manuscript.

\section{LITERATURE CITED}

Bentley ML, Mote TL (1998) A climatology of derecho producing mesoscale convective systems 1986-1995. Part I. Temporal and spatial distribution. Bull Am Meteorol Soc 79:2527-2540

Bentley ML, Mote TL (2000) A synoptic climatology of cool season derechos. Phys Geogr 21:21-37

Bentley ML, Mote TL, Byrd SF (2000) A synoptic climatology of derecho producing mesoscale convective systems (DMCSs) in the Northern Plains. Int J Climatol 20: 1329-1349

Editorial responsibility: Robert Davis, Charlottesville, Virginia, USA
Bosart LF, Bracken WE, Seimon A (1999) The evolution of warm season continental anticyclones and their contribution to derecho environments. In: Preprints, 17th Conf Weather Analysis and Forecasting, Denver, CO. American Meteorological Society, Denver, CO, p 100-103

Carleton AM, Song Y (1997) Synoptic climatology and intrahemispheric associations of cold air mesocyclones in the Australasian sector. J Geophys Res 102:13873-13887

Hart J (2000) Severe Plot 2.0. DOC/NOAA/NWS/NCEP, Storm Prediction Center, Norman, OK

Johns RH (1984) A synoptic climatology of northwest flow severe weather outbreaks. Part II. Meteorological parameters and synoptic patterns. Mon Weather Rev 112: $449-464$

Johns RH (1993) Meteorological conditions associated with bow echo development in convective storms. Weather Forecasting 8:294-299

Johns RH, Hirt WD (1987) Derechos: widespread convectively induced windstorms. Weather Forecasting 2:32-49

Johns RH, Evans JS (2000) Comments on 'A climatology of derecho-producing mesoscale convective systems in the central and eastern United States, 1986-95. Part I. Temporal and spatial distribution. Bull Am Meteorol Soc 81: 1049-1054

Kalnay E, Kanamitsu M, Kistler R, Collins W and 18 others (1996) The NCEP/NCAR 40-Year Reanalysis Project. Bull Am Meteorol Soc 77:437-472

Maddox RA (1983) Large-scale meteorological conditions associated with midlatitude, mesoscale convective complexes. Mon Weather Rev 111:1475-1493

Porter JM, Means LL, Hovde JE, Chappell WB (1955) A synoptic study of the formation of squall lines in the north central United States. Bull Am Meteorol Soc 36:390-396

Storm Data (1998) Vol 40, National Climatic Data Center, Asheville, NC

Trenberth KE (1983) What are the seasons? Bull Am Meteorol Soc 64:1276-1277

Weiss SJ, Vescio MD (1998) Severe local storm climatology 1955-1996: analysis of reporting trends and implications for NWS operations. In: Preprints, 19th Conf Severe Local Storms, American Meteorology Society, Minneapolis, MN, p 536-539

Submitted: August 10, 2002; Accepted: March 31, 2003 Proofs received from author(s): June 27, 2003 